\title{
Analysis of Ploidy Levels in Strains of Verticillium using a Coulter Counter
}

\author{
By M. A. TYPAS* AND J. B. HEALE \\ Department of Biology, Queen Elizabeth College, Campden Hill Road, London W8 7 AH
}

(Received 23 December 1976; revised 25 February 1977)

\section{INTRODUCTION}

Verticillium albo-atrum and $V$. dahliae are predominantly haploid and are classified as Fungi Imperfecti. Both species form verticillate conidiophores and develop darkly-pigmented resting structures; resting mycelium is produced by $V$. albo-atrum and microsclerotia by $V$. dahliae (Isaac, I967). Single spore analysis indicates that black parental $\left(\mathrm{Hyl}^{+}\right)$cultures of both species frequently yield small numbers of hyaline (white) colonies which include both partially hyaline $\left(\mathrm{Hyl}^{+} . \mathrm{p}\right)$ and completely hyaline (Hyl) forms. There is substantial evidence that the inheritance of darkly-pigmented resting structures in these fungi is under cytoplasmic control (Heale, I966; Typas \& Heale, 1976a,b).

Cytological investigations, including those of Robinson, Larson \& Walker (I957), Heale, Gafoor \& Rajasingham (I968) and Pelletier \& Aubé (I970), strongly indicate a uninucleate state for conidia of Verticillium. The percentage of binucleate spores was usually about I \% or less, although Roth \& Brandt (1964) reported a frequency as high as $15 \%$ for binucleate and multinucleate conidia in one hyaline strain. Hastie $(1964,1968)$ produced unstable heterozygous diploids through heterokaryons and demonstrated the occurrence of the parasexual cycle in this fungus.

In this paper we report on the use of the Coulter counter (Kubitschek, 1969) for reliably estimating the ploidy levels of large populations of conidia of V. albo-atrum and $V$. dahliae.

\section{METHODS}

Strains. The I 2 strains of Verticillium used are listed in Table I. Auxotrophs were produced by ultraviolet irradiation (Typas \& Heale, 1976b).

Media. Czapek-Dox agar served as minimal medium (MM) (Typas \& Heale, 1976b). Complete medium (CM) contained the constituents of MM with the addition of casein hydrolysate, yeast extract, peptone and malt extract (each at $2 \mathrm{~g}^{-1}$ ). Solid media contained $2 \%(\mathrm{w} / \mathrm{v})$ 'Japanese' agar. All cultures were grown at $24{ }^{\circ} \mathrm{C}$.

Heterokaryons and prototrophic heterozygous diploid conidia. Large numbers of spores sampled from heterokaryons yielded prototrophic heterozygous diploid conidia at a frequency of about $\mathrm{I}$ in $8 \times 10^{6}$ spores (Typas \& Heale, $1976 b$ ). Conidial volumes for spores from such prototrophic colonies on MM were analysed over a time course.

Ploidy levels. Ploidy levels were determined by examining 12000 to 16000 spores from each strain with a Coulter counter, model 2B, connected with a Coulter Channelyzer C-Ioo (Coulter Electronics, Dunstable, Bedfordshire). Both the $30 \mu \mathrm{m}$ and $50 \mu \mathrm{m}$ orifices were used and I ml of conidial suspension (adjusted to $\mathrm{I} \times 10^{6}$ conidia $\mathrm{ml}^{-1}$ ) was diluted in $9 \mathrm{ml}$ of Isoton (isotonic solution; Coulter Electronics) before screening the sample.

Conidia were also stained with Feulgen (Heale et al., 1968) and examined microscopically.

* Present address: Department of Biology, University of Athens, Panepistimioupolis - Kouponia, Athens (62I), Greece. 
Table I. Volumes of conidia from darkly-pigmented $\left(\mathrm{Hyl}^{+}\right)$, partially hyaline $\left(\mathrm{Hyl}^{+} . \mathrm{p}\right)$ and completely hyaline $(\mathrm{Hyl})$ prototrophic (wild-type) strains of $V$. albo-atrum and $V$. dahliae

Each volume result (Coulter counter data) gives the mean, with standard error, of five measurements, each corresponding to 12000 to 16000 conidia.

\begin{tabular}{|c|c|c|c|c|c|}
\hline \multirow[b]{2}{*}{ Species } & \multirow[b]{2}{*}{ Host plant } & \multirow[b]{2}{*}{ Location } & \multicolumn{3}{|c|}{ Mean conidial volume $\left(\mu \mathrm{m}^{3}\right)$} \\
\hline & & & $\mathrm{Hyl}^{+}$ & Hyl & $\mathrm{Hyl}^{+}, \mathrm{p}$ \\
\hline V. albo-atrum & Potato & Swansea & $17.88 \pm 0.18$ & $19.30 \pm 0.20$ & $17.52 \pm 0.14$ \\
\hline V. albo-atrum & Tomato & London & $15.84 \pm 0.14$ & $17.58 \pm 0.13$ & $16.49 \pm 0.17$ \\
\hline V. albo-atrum & Lucerne & Norfolk & $16 \cdot 37 \pm 0.25$ & $18.00 \pm 0.14$ & I $6.44 \pm 0.21$ \\
\hline V. albo-atrum & Chrysanthemum & Devonshire & $15.86 \pm 0.12$ & $18.6 I \pm 0.16$ & $16.04 \pm 0.16$ \\
\hline V. albo-atrum & Antirrhinum & Swansea & $17.83 \pm 0.13$ & $19.52 \pm 0.09$ & $17 \cdot 97 \pm 0.16$ \\
\hline$V$. dahliae & Pear & Australia & $12.62 \pm 0.12$ & $13.76 \pm 0.09$ & $12.85 \pm 0.15$ \\
\hline V. dahliae & Peppermint & U.S.A. & $12 \cdot 15 \pm 0 \cdot 10$ & $13.15 \pm 0.13$ & $12.40 \pm 0.12$ \\
\hline V. dahliae & Sunflower & Swansea & II.56士0.II & $13.34 \pm 0.15$ & II $62 \pm 0.11$ \\
\hline$V$. dahliae & Cotton & U.S.A. & $11 \cdot 37 \pm 0 \cdot 13$ & $13 \cdot 12 \pm 0.15$ & II $.95 \pm 0.17$ \\
\hline V. dahliae & Potato & Swansea & II $6 I \pm 0 \cdot 16$ & $12.89 \pm 0.19$ & $10.92 \pm 0.18$ \\
\hline V. dahliae & Sprout & Evesham & $11 \cdot 98 \pm 0 \cdot 10$ & $12.98 \pm 0.18$ & II $\cdot 02 \pm 0.12$ \\
\hline $\begin{array}{l}V . \text { dahliae var. } \\
\text { longisporum* }\end{array}$ & Horseradish & Germany & $38.67 \pm 0.19$ & $39.73 \pm 0.22$ & $38.50 \pm 0.21$ \\
\hline
\end{tabular}

$\mathrm{Hyl}^{+}$, Wild-type phenotype producing normal amounts of dark pigmentation as when first isolated from the diseased host.

$\mathrm{Hyl}^{+}$.p, Partially hyaline, producing very small amounts of pigment (as dots around the centre of the culture); obtained from the $\mathrm{Hyl}^{+}$wild-type by ultraviolet irradiation or acriflavine treatment (Typas \& Heale, $1976 a$ ).

Hyl, Stable hyaline strains, not producing pigment and resting structures; obtained from $\mathrm{Hyl}^{+}$by ultraviolet irradiation or acriflavine treatment.

* V. dahliae var. longisporum (Stark, 196I) is a naturally-occurring diploid strain (Ingram, I968) and was kindly supplied by Dr A. C. Hastie.

\section{RESULTS AND DISCUSSION}

The volume data (Table I) indicate that there was no significant difference in spore size between strains belonging to the same pigmentation class of the same species. Comparison of the mean values for all haploid strains of the $\mathrm{Hyl}^{+}$type shows a constant spore size difference between $V$. albo-atrum and $V$. dahliae, with the former being relatively larger, namely $5.16 \pm 0.09 \mu \mathrm{m}$ (length) and $16.75 \pm 0.16 \mu \mathrm{m}^{3}$ (volume) compared with $4.55 \pm 0.07 \mu \mathrm{m}$ and II $87 \pm 0 \cdot I_{2} \mu \mathrm{m}^{3}$ respectively for $V$. dahliae. It might therefore be possible to distinguish between the two species on these grounds. However, this is not considered to be a major criterion and it should obviously be accompanied by a series of other observations, i.e. dark pigmentation in the base of the conidiophores, temperature response, appearance of dark resting mycelium for $V$. albo-atrum and microsclerotia for $V$. dahliae (Heale \& Isaac, 1965; Schnathorst, 1973; Typas, 1976).

Size distribution curves of conidial samples from the $V$. dahliae var. longisporum strain confirmed the difference in ploidy level between this natural diploid strain (Ingram, 1968) and all other wild-type haploid strains of $V$. dahliae tested. A few investigators have also observed conidial lengths which might suggest the natural occurrence of diploids (Chaudhuri, 1923; Van der Meer, 1925).

Mean data for spores from Hyl strains of both species suggested that they were slightly larger (about $4 \%$ in length and $14 \%$ in volume) than those from either $\mathrm{Hyl}^{+}$or $\mathrm{Hyl}^{+} . \mathrm{p}$ pigmented strains, the latter two types being indistinguishable on this basis. This was probably due to the higher frequency (up to $3 \%$ ) of bi- and multinucleate conidia recorded for Hyl strains compared with less than I \% for dark parental types. Tolmsoff's (1973) suggestion that a mixture of ploidy within the same strain accompanied the formation of resting structures therefore remains unsubstantiated. 


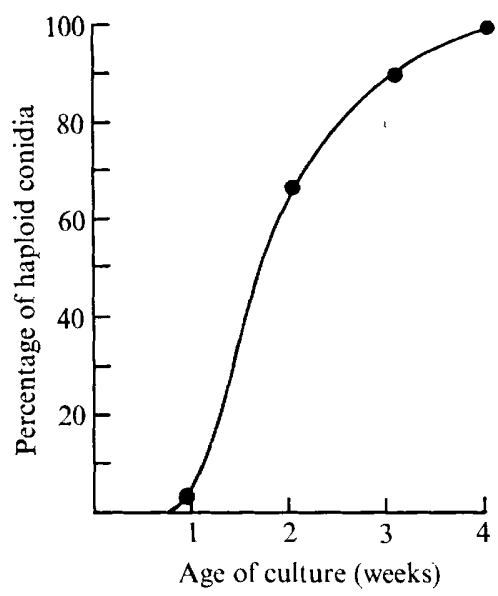

Fig. I. The effect of culture age on average frequencies of haploid conidia in segregating heterozygous diploid cultures of $V$. dahliae and $V$. albo-atrum. Data represent the means for eight different heterozygous diploid cultures.

Conidial suspensions from auxotrophic colonies of the $\mathrm{Hyl}^{+}$and $\mathrm{Hyl}$ types showed size distributions which were indistinguishable from those obtained from the parental prototrophic $\mathrm{Hyl}^{+}$and $\mathrm{Hyl}$ colonies respectively.

Analysis of conidial samples from I-week-old prototrophic colonies, recovered after plating conidia from heterokaryons at very high density on MM, resulted in size distribution curves and volume data which invariably indicated diploidy, being similar to those obtained from $V$. dahliae var. longisporum.

Once spore-size distributions of both haploid and diploid conidial populations were established, it was possible to prepare a series of standard curves from conidial samples with a range of given haploid/diploid ratios, i.e. $100 \%$ haploid $0 \%$ diploid, $90 \%$ haploid $10 \%$ diploid, $80 \%$ haploid $20 \%$ diploid etc. These curves, which were of a bimodal type, enabled us to estimate the haploid/diploid ratio in an unknown sample; the sensitivity was such that a level of diploidy down to $2-3 \%$ was still just detectable.

Changes in spore size, which tended towards a bimodal distribution, were noted in conidial samples taken from prototrophic heterozygous diploid cultures over a growth period of 4 weeks. The proportion of diploid conidia (Fig. I) fell markedly in the second and third week and by the end of the fourth week almost all the conidia were haploid.

The peak of the curve for conidia from the stable diploid $V$. dahliae var. longisporum was relatively smooth in contrast to those obtained from segregating heterozygous diploid cultures which appeared to show very small side peaks on either side of the main one, presumably indicating the presence of various aneuploid states. Investigations on nuclear behaviour in phialides (Hastie, 1967, 1968) have indicated that haploid genotypes are not formed directly from diploids but through intermediate aneuploid stages.

Examination of conidia of wild-type darkly-pigmented $\left(\mathrm{Hyl}^{+}\right)$haploid strains of both species after Feulgen staining revealed nuclear diameters ranging from about $\mathrm{I} \cdot 0$ to $\mathrm{I} \cdot \mathrm{I} \mu \mathrm{m}$; the diameters of nuclei in conidia of $V$. dahliae var. longisporum and all prototrophic heterozygous diploid strains were estimated to be in the range $\mathrm{I} \cdot 8$ to $2 \cdot 0 \mu \mathrm{m}$.

Among a large number of fungi, only Cephalosporium mycophilum (Tuveson \& Coy, I96I) spontaneously yields high proportions of haploid segregants from heterozygous diploids similar to those found for Verticillium. The frequency of haploids recovered in our work may be attributed mainly to a high haploidization frequency, but also at least in part to the prolific sporulation observed in the haploid, as opposed to the diploid, mycelium of Verticillium. 
Spore size, therefore, is a convenient criterion for reliably establishing the level of ploidy. Such an approach should always be verified by cytological checks of nuclear-stained conidia, as well as by genetic analysis. In future experiments, single spore analysis and screening of large conidial samples from wild-type Verticillium isolates could lead to estimations of the frequency at which diploids might be found in natural populations. Further, the discovery of large-spored variants which give bimodal spore-size distributions (similar to those obtained here from rapidly segregating heterozygous diploids) would be the simplest way of demonstrating the occurrence of the parasexual cycle under field conditions in this, and possibly other, fungi.

We would like to thank Dr A. C. Hastie for his interest in this work.

\section{REFERENCES}

Chaudhuri, J. (1923). A study of the growth in culture of Verticillium albo-atrum $\mathrm{R}$ et B. Annals of Botany 37, 5I9-539.

HASTIE, A.C. (I964). The parasexual cycle in Verticillium albo-atrum. Genetical Research 5, 305-3I5.

HASTIE, A. C. (1967). Mitotic recombination in conidiophores of Verticillium albo-atrum. Nature, London 214, 249-252.

Hastie, A. C. (I968). Phialide analyses of mitotic recombination in Verticillium. Molecular and General Genetics 102, 232-240.

Heale, J. B. (1966). Heterokaryon synthesis in Verticillium. Journal of General Microbiology 45, 419-427.

Heale, J. B. \& IsaAC, I. (1965). Environmental factors in the production of dark resting structures in $V$. albo-atrum, $V$. dahliae and $V$. tricorpus. Transactions of the British Mycological Society 48, 39-50.

Heale, J. B., Gafoor, A. \& Rajasingham, K. C. (I968). Nuclear division in conidia and hyphae of Verticillium albo-atrum. Canadian Journal of Genetics and Cytology 10, $32 \mathrm{I}-340$.

INGRAM, R. (1968). Verticillium dahliae Kleb. var. longisporum Stark a stable diploid. Transactions of the British Mycological Society 51, 339-341.

IsAAC, I. (1967). Speciation in Verticillium. Annual Review of Phytopathology 5, 201-222.

KubrTSCHEK, H. E. (1969). Counting and sizing microorganisms with the Coulter counter. Methods in Microbiology I, 593-610.

Pelletier, G. \& Aubé, C. (I970). Conidial size and contents in Verticillium as affected by environmental factors. Canadian Journal of Microbiology I6, $231-236$.

Robinson, D. B., LaRSON, R. H. \& Walker, J. C. (1957). Verticillium wilt of potato in relation to symptoms, epidemiology and variability of the pathogen. Wisconsin Agricultural Experimental Station Research Bulletin 202, I-49.

RoTH, J. N. \& BRANDT, W. H. (1964). Influence of some environmental factors on hereditary variation in monospore cultures of Verticillium alboatrum. Phytopathology 54, I454-1458.

SCHNATHORST, W. C. (1973). Nomenclature and physiology of Verticillium species with emphasis on the $V$. albo-atrum versus $V$. dahliae controversy. In Verticillium Wilt of Cotton, Proceedings of a Work Conference, National Cotton Pathology Research Laboratory, College Station, Texas, I97I (ARS-S-19), pp. I-19.

STARK, C. (196I). Das Auftreten der VerticilliumTracheomykosen in Hamburger Gartenbaukulturen. Gartenbauwissenschaft 26, 493-528.

TOLMSOFF, W. J. (1973). Life cycles of Verticillium species. In Verticillium Wilt of Cotton, Proceedings of a Work Conference, National Cotton Pathology Research Laboratory, College Station, Texas, 1971 (ARS-S-19), pp. 20-38.

Tuveson, R. W. \& CoY, D. O. (196I). Heterocaryosis and somatic recombination in Cephalosporium mycophilum. Mycologia 53, 244-253.

TyPAS, M. A. (1976). Genetical aspects of the mechanisms of variation and differentiation in species of Verticillium. Ph.D. thesis, University of London.

Typas, M. A. \& Heale, J. B. (I976a). Acriflavineinduced hyaline variants of Verticillium alboatrum and $V$. dahliae. Transactions of the British Mycological Society 66, 15-25.

Typas, M. A. \& Heale, J. B. (1976b). Heterokaryosis and the role of cytoplasmic inheritance in dark resting structure formation in Verticillium $\mathrm{spp}$. Molecular and General Genetics 146, 17-26.

VAN DER MEER, J. H. H. (1925). Verticillium wilt of herbaceous and woody plants. Mededelingen van de Landbouwhoogeschool te Wageningen 28, I-82. 